\title{
An MLSA-based online scheme for the rapid identification of Stenotrophomonas isolates
}

\author{
Patrícia Locosque Ramos ${ }^{1,2} /{ }^{+}$, Carlos Alberto Moreira-Filho ${ }^{1,2}$, \\ Stefanie Van Trappen ${ }^{3}$, Jean Swings ${ }^{3}$, Paul De Vos ${ }^{3}$, Heloiza Ramos Barbosa ${ }^{4}$, \\ Cristiane Carneiro Thompson ${ }^{5}$, Ana Tereza Ribeiro Vasconcelos ${ }^{6}$, Fabiano Lopes Thompson ${ }^{5}$
}

\footnotetext{
${ }^{1}$ Departamento de Pediatria, Faculdade de Medicina ${ }^{2}$ Centro de Pesquisas em Biotecnologia ${ }^{4}$ Departamento de Microbiologia, Instituto de Ciências Biomédicas, Universidade de São Paulo, Av. Dr. Enéas Carvalho Aguiar 647, 01246-903 São Paulo, SP, Brasil ${ }^{3}$ Laboratory of Microbiology, Belgian Co-ordinated Collections of Micro-organisms, Bacteria Collection, Ghent University, Ghent, Belgium ${ }^{5}$ Departamento de Genética, Instituto de Biologia, Universidade Federal do Rio de Janeiro, Rio de Janeiro, RJ, Brasil

${ }^{6}$ Departamento de Matemática Aplicada e Computacional, Laboratório Nacional de Computação Científica, Petrópolis, RJ, Brasil
}

An online scheme to assign Stenotrophomonas isolates to genomic groups was developed using the multilocus sequence analysis (MLSA), which is based on the DNA sequencing of selected fragments of the housekeeping genes ATP synthase alpha subunit (atpA), the recombination repair protein $(\mathrm{rec} A)$, the RNA polymerase alpha subunit ( $\mathrm{rpo} A$ ) and the excision repair beta subunit ( $\mathrm{uvr} B$ ). This MLSA-based scheme was validated using eight of the 10 Stenotrophomonas species that have been previously described. The environmental and nosocomial Stenotrophomonas strains were characterised using MLSA, $16 S$ rRNA sequencing and DNA-DNA hybridisation (DDH) analyses. Strains of the same species were found to have greater than $95 \%$ concatenated sequence similarity and specific strains formed cohesive readily recognisable phylogenetic groups. Therefore, MLSA appeared to be an effective alternative methodology to amplified fragment length polymorphism fingerprint and DDH techniques. Strains of Stenotrophomonas can be readily assigned through the open database resource that was developed in the current study (www.steno.lncc.br/).

Key words: Stenotrophomonas - MLSA - online scheme

The genus Stenotrophomonas is widespread in the environment and exists as a free-living and plant-associated organism as well as an opportunistic pathogen (Falagas et al. 2008, Nyc \& Matejková 2010). Therefore, Stenotrophomonas displays great metabolic versatility and intraspecific heterogeneity (Ryan et al. 2009). The species Stenotrophomonas maltophilia is an important nosocomial pathogen (Nicodemo \& Paez 2007) that is correlated with a high mortality rate among immunocompromised patients (Araoka et al. 2010). The impact of S. maltophilia as a multidrug-resistant pathogen has significantly increased (Hauben et al. 1999, Sanchez et al. 2009), which highlights the importance of rapid and reliable isolate identification. Moreover, endophytic Stenotrophomonas spp have an important role in plant development in a variety of economically important agricultural species (Vega et al. 2005) by producing hormones, growth factors and $\mathrm{N}_{2}$ for their hosts. Some strains of this genus are used as biocontrol agents against pathogenic fungi and yeasts in plants (Minkwitz \& Berg 2001). In addition, some Stenotrophomonas rhizophila strains can degrade xenobiotic compounds and are used in the bioremediation of contaminated soils (Juhasz \& Naidu 2000).

Financial support: CNPq (300996/2006-7), FAPESP (2004/00814-9), CNPq and IFS (to FLT), FAPESP (Biota Program) (to CAMF)

+Corresponding author: locosque@usp.br

Received 11 September 2010

Accepted 20 April 2011
Ten species of Stenotrophomonas have been described as follows: S. maltophilia (Palleroni \& Bradbury 1993), which was identified in soils, plants and in nosocomial infections (Ryan et al. 2009), Stenotrophomonas nitritireducens, which was isolated from ammonia-supplied biofilters (Finkmann et al. 2000), S. rhizophila, which was isolated from the rhizosphere of rape plants (Wolf et al. 2002), Stenotrophomonas acidaminiphila (Assih et al. 2002), which was originally found in a labscale methanogenic reactor that treated industrial wastewater, Stenotrophomonas koreensis (Yang et al. 2006), which was isolated from compost in Daejeon (South Korea), and Stenotrophomonas terrae and Stenotrophomonas humi, which were described to encompass nitratereducing isolates that were obtained from soil samples in Ghent, Belgium (Heylen et al. 2007). The Stenotrophomonas chelatiphaga strain was isolated from sewage sludge in Kazan City, Russian Federation (Kaparullina et al. 2009). The Stenotrophomonas pavanii strain was isolated from sugar cane cultivars in Brazil (Ramos et al. 2011). Recently, the Stenotrophomonas ginsengisoli strain was isolated from the soil of a ginseng field in South Korea (Kim et al. 2010).

The precise identification and classification of Stenotrophomonas remains a problem. Band pattern methods [e.g., amplified fragment length polymorphism (AFLP)] and DNA-DNA hybridisation (DDH) techniques have been used to underpin the taxonomy of this group. However, the data that are generated by these tools are often difficult to reproduce and are available only in a few laboratories (Coenye et al. 2004a). In addition, the data that are generated by these methods cannot be used 
to build an online electronic classification. These limitations can be overcome by the use of multilocus sequence typing (MLST), which uses the DNA sequence variation in seven or more housekeeping genes to characterise bacterial strains based on their unique allelic profiles (Maiden et al. 1998, Turner \& Feil 2007). A simplified approach to MLST, which is widely applied in microorganism identification, uses only three-five housekeeping genes (Hanage et al. 2006, Brady et al. 2008) and is known as multilocus sequence analysis (MLSA). MLSA differs from MLST in the way the data are analysed. In MLSA, the sequence concatenation is used instead of the allelic profiles and the dataset includes multiple species collections. MLSA has been successfully used for species identification in several genera such as Vibrio (Thompson et al. 2005), Enterococcus (Naser et al. 2005) and the viridans group of Streptococcus (Bishop et al. 2009). The online scheme that is proposed in the current study is based on the DNA sequencing of selected fragments of the genes coding for the ATP synthase alpha subunit $(\operatorname{atpA})$, the recombination repair protein $(r e c \mathrm{~A})$, the RNA polymerase alpha subunit $(r p o \mathrm{~A})$ and the excision repair beta subunit $(u v r \mathrm{~B})$. This scheme allows for the rapid identification of Stenotrophomonas isolates through assignment to the genomic groups of the genus (Hauben et al. 1999, Coenye et al. 2004b).

\section{MATERIALS AND METHODS}

Bacterial strains and the isolation of DNA - All of the type strains of the genus Stenotrophomonas that were used for MLSA were deposited in the $\mathrm{BCCM}^{\mathrm{TM}} / \mathrm{LMG}$ Bacteria Collection and in our own research collection at the University of São Paulo (Table I). The genomic bacterial DNA was isolated using the Wizard Genomic DNA Purification Kit (Promega, Madison, WI, USA: Cat. A 1120 ), according to the manufacturer's instructions.

TABLE I

Strains used in this study

\begin{tabular}{|c|c|c|c|c|c|}
\hline Strain number & Stenotrophomonas species & Source & $\begin{array}{l}\text { MLSA } \\
\text { cluster }\end{array}$ & $\begin{array}{l}\text { Genomic } \\
\text { group }\end{array}$ & Reference \\
\hline LMG $958^{\mathrm{T}}$ & Stenotrophomonas maltophilia & Oral cancer & MLSA 1 & 6 & Pallerony and Bradbury (1993) \\
\hline LMG 22072 & Stenotrophomonas maltophilia & HIV positive patient & MLSA 1 & ND & Drancourt et al. (1997) \\
\hline LMG $22075^{\mathrm{T}}$ & Stenotrophomonas rhizophila & Rhizosphere of rape & MLSA 1 & ND & Wolf et al. (2002) \\
\hline LMG 10996 & Stenotrophomonas sp. & Leg, ulcer & MLSA 1 & 2 & - \\
\hline LMG $978^{\mathrm{T}}$ & Pseudomonas beteli & Piper beetle & MLSA 1 & ND & - \\
\hline LMG $980^{\mathrm{T}}$ & Pseudomonas hibiscicola & Hibiscus rosa-sinensis & MLSA 1 & ND & - \\
\hline LMG 10874 & Stenotrophomonas sp. & Human blood culture & MLSA 1 & 4 & - \\
\hline LMG 10878 & Stenotrophomonas sp. & Patient with otitis, pus & MLSA 1 & 4 & - \\
\hline LMG 11002 & Stenotrophomonas sp. & Mamilla & MLSA 1 & 3 & - \\
\hline LMG 10991 & Stenotrophomonas sp. & Leg, pus & MLSA 1 & 2 & - \\
\hline LMG25348 & Stenotrophomonas pavanii & Sugarcane & MLSA 1 & - & Ramos et al. (2011) \\
\hline ICB 194 & Stenotrophomonas sp. & Sugarcane & MLSA 1 & ND & - \\
\hline LMG 10851 & Stenotrophomonas sp. & Human blood culture & MLSA 2 & 5 & - \\
\hline LMG 10877 & Stenotrophomonas sp. & Patient with sinusitis, pus & MLSA 2 & 5 & - \\
\hline LMG 11089 & Stenotrophomonas sp. & Rhizosphere tuberous root & MLSA 2 & 5 & - \\
\hline LMG $23959^{\mathrm{T}}$ & Stenotrophomonas humi & Soil & MLSA 3 & ND & Heylen et al. (2007) \\
\hline LMG $23958^{\mathrm{T}}$ & Stenotrophomonas terrae & Soil & MLSA 3 & ND & Heylen et al. (2007) \\
\hline LMG 6608 & Stenotrophomonas sp. & Rhizosphere & MLSA 4 & 9 & - \\
\hline LMG 11087 & Stenotrophomonas sp. & Rhizosphere & MLSA 4 & 9 & - \\
\hline LMG $22073^{\mathrm{T}}$ & Stenotrophomonas acidaminiphila & UASB reactor & MLSA 5 & ND & Assih et al. (2002) \\
\hline LMG $22074^{\mathrm{T}}$ & Stenotrophomonas nitritireducens & Biofilter & MLSA 5 & ND & Finkmann et al. (2000) \\
\hline LMG 10881 & Stenotrophomonas sp. & Fish & MLSA 5 & ND & - \\
\hline LMG 10882 & Stenotrophomonas sp. & Sewage & MLSA 5 & ND & - \\
\hline LMG 10883 & Stenotrophomonas sp. & Frozen fruit & MLSA 5 & 1 & - \\
\hline DSMZ $17805^{\mathrm{T}}$ & Stenotrophomonas koreensis & Compost & MLSA ND & - & Yang et al. (2006) \\
\hline KT2440 & Pseudomonas putida & - & Outgroup & - & - \\
\hline ATCC 33913 & Xanthomonas campestris & - & Outgroup & - & - \\
\hline $9 a 5 c$ & Xylella fastidiosa & - & Outgroup & - & - \\
\hline
\end{tabular}

HIV: human immunodeficiency virus; MLSA: multilocus sequence analysis; ND: not determined; UASB: upflow anaerobic sludge blanket. 
The amplification and sequencing of housekeeping and 16S rRNA genes - Approximately 50 ng of DNA were used as the PCR template for the amplification of selected fragments of the genes atp $\mathrm{A}, r e c \mathrm{~A}, r p o \mathrm{~A}$ and $u v r \mathrm{~B}$. The primers that were used in the current study and the respective annealing temperatures are listed in Table II. Because the complete Stenotrophomonas genome sequences are only available for two of the S. maltophilia strains (NC 011071 and NC 010943) (Crossman et al. 2008), the primer design (using the software Kodon, Applied Maths) included gene sequences of Xanthomonas axonopodis, Xanthomonas campestris, Xylella fastidiosa, Pseudomonas aeruginosa, Pseudomonas putida, Pseudomonas syringae, Mesorhizobium loti, Sinorhizobium meliloti, Brucella melitensis, Brucella suis, Ralstonia solanacearum and Agrobacterium tumefaciens.

The polymerase chain reaction (PCR) for the housekeeping genes was composed of $38.2 \mu \mathrm{L}$ of sterile MilliQ water, $1.5 \mu \mathrm{L}$ of $\mathrm{MgCl}_{2}\left(1.5 \mathrm{mmol} \cdot \mathrm{LL}^{-1}\right), 5.0 \mu \mathrm{L}$ of PCR buffer (10X), $0.4 \mu \mathrm{L}$ of dNTPs $\left(0.2 \mathrm{mmol} \cdot \mu \mathrm{L}^{-1}\right.$ each), $1.2 \mu \mathrm{L}$ of the forward primer $\left(20 \mu \mathrm{mol} \cdot \mu \mathrm{L}^{-1}\right), 1.2 \mu \mathrm{L}$ of the reverse primer $20 \mu \mathrm{mol}^{-1} \cdot \mu \mathrm{L}, 0.4 \mu \mathrm{L}$ of the Taq DNA Polymerase $\left(2 \mathrm{U} \cdot \mu \mathrm{L}^{-1}\right)$ and $2.0 \mu \mathrm{L}$ of the template DNA $\left(0.05 \mu \mathrm{g} \cdot \mu \mathrm{L}^{-1}\right)$. The thermal program consisted of one cycle of $5 \mathrm{~min}$ at $95^{\circ} \mathrm{C}$, three cycles of $1 \mathrm{~min}$ at $95^{\circ} \mathrm{C}$, $2 \mathrm{~min} 15 \mathrm{~s}$ at $55^{\circ} \mathrm{C}$ and $1 \mathrm{~min} 15 \mathrm{~s}$ at $72^{\circ} \mathrm{C}, 30$ cycles of 30 $\mathrm{s}$ at $95^{\circ} \mathrm{C}, 1 \mathrm{~min} 15 \mathrm{~s}$ at $55^{\circ} \mathrm{C}$ and $1 \mathrm{~min} 15 \mathrm{~s}$ at $72^{\circ} \mathrm{C}$ and a final extension cycle of $7 \mathrm{~min}$ at $72^{\circ} \mathrm{C}$. The amplification of 16S rRNA was performed using 30-50 ng of DNA in $50-\mu \mathrm{L}$ reactions containing $2 \mathrm{mmol} \cdot \mu \mathrm{L}^{-1} \mathrm{MgCl}_{2}, 200$ $\mu \mathrm{mol} \cdot \mu \mathrm{L}^{-1} \mathrm{dNTPs}$ (each), $0.3 \mu \mathrm{mol} \cdot \mu \mathrm{L}^{-1}$ of each of the universal primers 27f (5'AGAGTTGATCCTGGCTCAG3') and 1525r (5'AAGGAGGTGWTCCARCC3') and 2U of the Taq DNA polymerase (Invitrogen) in the recommended buffer. The reaction mixtures were incubated in a thermal cycler Eppendorf Master Cycler Gradient (Eppendorf AG, Hamburg, Germany) at $94^{\circ} \mathrm{C}$ for $2 \mathrm{~min}$ and then cycled 30 times at $94^{\circ} \mathrm{C}$ for $1 \mathrm{~min}, 55^{\circ} \mathrm{C}$ (annealing temperature) for $1 \mathrm{~min}$ and $72^{\circ} \mathrm{C}$ for $3 \mathrm{~min}$. A final extension at $72^{\circ} \mathrm{C}$ for $10 \mathrm{~min}$ was used. All of the PCR products were purified using the GFX PCR DNA and Gel Band Purification Kit (GE Healthcare, Uppsala, cat. 28-9034-70). Subsequently, $5.0 \mu \mathrm{L}$ of the purified PCR product was mixed with $4.0 \mu \mathrm{L}$ of the solution from the DYEnamicTM ET dye terminator kit MegaBACE ${ }^{\mathrm{TM}}$ 1000 (GE Healthcare) and $1.0 \mu \mathrm{L}$ of the sequencing primer $\left(0.5 \mu \mathrm{mol} \cdot \mu \mathrm{L}^{-1}\right)$. The thermal program consisted of 30 cycles of $20 \mathrm{~s}$ at $95^{\circ} \mathrm{C}, 15 \mathrm{~s}$ at $55^{\circ}$ and $60 \mathrm{~s}$ at $60^{\circ}$. The sequencing products were purified according to the manufacturer's instructions.

The comparison between the housekeeping genes and $16 S$ rRNA and the phylogenetic analysis - Stenotrophomonas bacteria were further characterised by partial sequencing of atpA (600 nt), recA (420 nt), rpoA (690 nt) and $u v r \mathrm{~B}(1219 \mathrm{nt})$. The Chromas Pro 1.34 software was used to obtain the consensus sequences for the housekeeping genes and $16 \mathrm{~S}$ rRNA. At least three reads were performed to obtain the consensus sequences. The consensus sequences were aligned using ClustalW (Altschul et al. 1990). The phylogenetic trees were created based on the maximum-parsimony (MP) and neighbour-joining (NJ) methods (Saitou \& Nei 1987) using the software MEGA 4. We also separately analysed each of the housekeeping gene sequences and compared the resulting topologies with the topology that was obtained from the concatenated gene tree. The robustness of each topology was checked using 1,000 bootstrap replications. The type strain sequences of $P$. putida, X. campestris and X. fastidiosa were considered outliers because of their phylogenetic similarities with those of Stenotrophomonas spp.

Split tree decomposition analysis and the Phi test were performed with SplitsTree4 (Huson 1998). The guanine-cytosine content, the ratio of the mean synonymous substitutions per the synonymous site to the mean non-synonymous substitutions per the non-synonymous site $(d \mathrm{~s} / d \mathrm{n})$ and the recombination tests were calculated using the software package START (pubmlst.org/software/analysis/start/) (Jolley et al. 2001).

$D D H$ - DDH experiments (Supplementary data) were performed to confirm the sequence data for the Stenotrophomonas isolates. A modification of the microplate

TABLE II

Amplification and sequencing primers used in this study

\begin{tabular}{|c|c|c|c|c|}
\hline Primer & Sequence (5'-3') & Position & $\begin{array}{l}\mathrm{GC} \\
(\%)\end{array}$ & $\begin{array}{l}\text { PCR annealing temperature } \\
\qquad\left({ }^{\circ} \mathrm{C}\right)\end{array}$ \\
\hline atpA-03-F & CGCATCCTBGARGTKCCG & 283 & 64.8 & 68 \\
\hline atpA-07-R & GCRCGCTCSAGCARRCG & 892 & 73.5 & 68 \\
\hline rec $\mathrm{A}-05-\mathrm{F}$ & GGYGAGATGGGMGAYCAG & 466 & 63.9 & 60 \\
\hline recA-07-R & TTKCCYTGSCCGATSCGCTC & 889 & 65 & 60 \\
\hline rpoA-01-F & TKAAGGATGTGGCRATCC & 254 & 52.6 & 62 \\
\hline rpoA-04-R & GGCCARTTCTCCARCTTCA & 944 & 55 & 62 \\
\hline$u v r \mathrm{~B}-01-\mathrm{F}$ & GARYAYATYGARCARATGCG & 381 & 45 & 58 \\
\hline$u v r \mathrm{~B}-02-\mathrm{R}$ & CCYTCYTTRTCDGCRTC & 1600 & 54.9 & 58 \\
\hline
\end{tabular}

F: forward; GC: guanine-cytosine content; PCR: polymerase chain reaction; R: reverse. 
method of Ezaki et al. (1989) that was described by Willems et al. (2001) was used. The hybridisation temperature was $45^{\circ} \mathrm{C}$ (calculated with the correction for the presence of $50 \%$ formamide).

Nucleotide sequence accession numbers - The gene sequences of the strains that were received from Laboratory of Microbiology/Belgian Co-ordinated Collections of Micro-organisms, Pasteur Institute, German Collection of Microorganisms and Cell Cultures and the University of São Paulo Biomedical Sciences Institute collections were previously deposited in the GenBank. The sequence data are also available at our website www.steno.lncc.br.

\section{RESULTS}

A broad collection of Stenotrophomonas strains was molecularly analysed to evaluate the usefulness of MLSA. The 16S rRNA results (data not shown) confirm that all of the strains and isolates that were used in the current work belong to the genus Stenotrophomonas, with the exception of the strains LMG $978^{\mathrm{T}}$ (Pseudomonas beteli) and LMG $980^{\mathrm{T}}$ (Pseudomonas hibiscicola). The genes that were analysed in the current study are typical housekeeping genes, which were shown by the relatively high $d \mathrm{~s} / d \mathrm{n}$ ratios and apparently have not undergone recombination (Table III). The NJ and MP methods were used to obtain the phylogenetic trees that were based on the concatenated sequences of atpA, $r e c \mathrm{~A}, r p o \mathrm{~A}$ and $u v r \mathrm{~B}$. The strain clusters that were generated were consistent with the former taxonomic studies in Stenotrophomonas spp strains. Overall, we found five Stenotrophomonas genomic groups (Figure), which were named MLSA I-V, that correspond to the AFLP groups that were described by Hauben et al. (1999). The topological analysis for each of the housekeeping gene sequences yielded essentially the same strain clusters with a few differences in the relative position of some clusters (Supplementary data). The DNA-DNA relatedness experiments showed $70 \%$ DNA-DNA binding for three strains (Supplementary data), which may indicate the presence of new species or a single species that is composed of heterogenic strains. Our results are clearly below the $70 \%$ DNA-DNA binding cut-off value for species delineation (Wayne et al. 1987).

\section{TABLE III}

Summary of gene features

\begin{tabular}{lcccc}
\hline Genes & $\begin{array}{c}\text { Length } \\
(\mathrm{nt})\end{array}$ & $d \mathrm{~s} / \mathrm{dn}$ & $\begin{array}{c}\mathrm{GC} \\
(\%)\end{array}$ & Recombination \\
\hline atpA & 316 & 7.2 & $63.4 \pm 0.8$ & $>0.05$ \\
recA & 379 & 59.1 & $58.0 \pm 1.4$ & $>0.05$ \\
rpoA & 314 & 11.7 & $66 \pm 3.3$ & $>0.05$ \\
uvrB & 182 & 4.3 & $61.3 \pm 2.9$ & $>0.05$ \\
\hline
\end{tabular}

$d \mathrm{~s} / d \mathrm{n}$ : the ratio of the mean synonymous substitutions per the synonymous site to the mean non-synonymous substitutions per the non-synonymous site; GC: guanine-cytosine content.

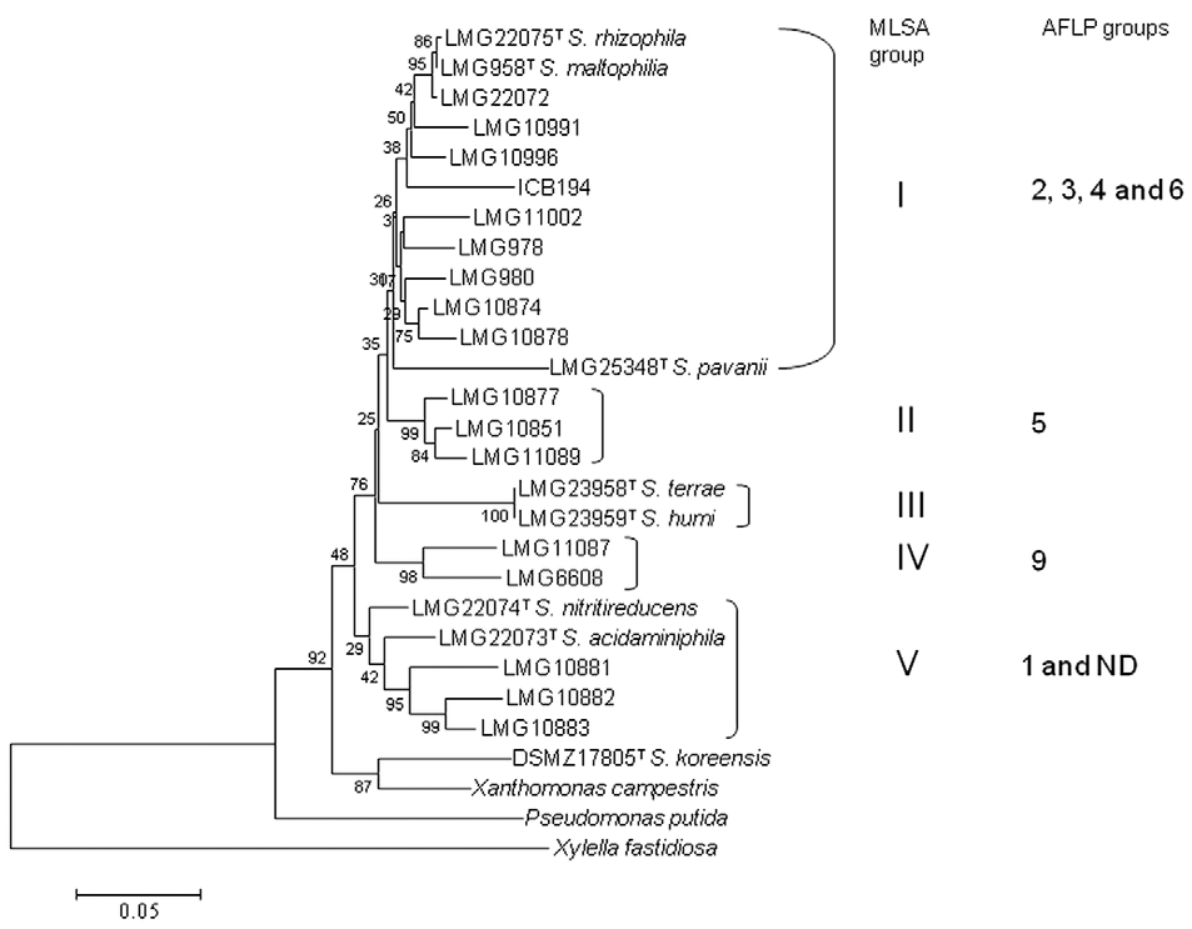

Consensus Neighbour-Joining phylogenetic tree based on the concatenated genes sequences of $r e c \mathrm{~A}, r p o \mathrm{~A}, u v r \mathrm{~B}$ and atpA. Values of bootstrap after 1,000 repetitions are shown at the nodes. Pseudomonas putida, Xanthomonas campestris and Xylella fastidiosa were used as out-groups. AFLP: amplified fragment length polymorphism; MLSA: multilocus sequence analysis; ND: not determined. 
The MLSA I group encompassed three type strains: LMG $958^{\mathrm{T}}\left(\right.$ S. maltophilia), LMG $22075^{\mathrm{T}}$ (S. rhizophila) and LMG $25348^{\mathrm{T}}$ (S. pavanii). These strains have been grouped based on the 16S rRNA sequence analysis (Heylen et al. 2007, Ramos et al. 2011). The MLSA I group included nine other strains that were already described as members of the AFLP genomic groups 2, 3, 4 and 6 that were characterised by Hauben et al. (1999). The strains LMG 10996 and LMG 10991 also showed a high degree of similarity (84\%) based on DDH results, consistent with previously reported levels (Hauben et al. 1999). The LMG 10996 strain in this group appears to be a putative new species considering our preliminary data of phenotypic tests (data not shown) and DDH results (Supplementary data). The MLSA II group contained three strains that belonged to Hauben's AFLP group 5 (LMG 10877, LMG 10851 and LMG 11089). These strains share $98.8 \%$ of similarity in their 16S rRNA sequences (Hauben et al. 1999). The comparison of two of these strains (LMG 10877 and LMG 10851) using the DDH technique revealed only $58 \%$ homology (Hauben et al. 1999).

The MLSA III group harboured the two strains S. humi and $S$. terrae, which have $44.2 \%$ DDH similarity (Heylen et al. 2007). These strains displayed high similarity levels in the 16S rRNA sequences (Heylen et al. 2007). The MLSA IV group is formed by two strains (LMG 6608 and LMG 11087). These strains showed $74 \%$ and $99 \%$ homology based on the DDH and the 16S rRNA sequencing, respectively. The MLSA IV group corresponded to Hauben's genomic group 9 (Hauben et al. 1999).

The MLSA V group included the two closely related strains $S$. acidaminiphila (LMG $22073^{\mathrm{T}}$ ) and S. nitritireducens (LMG 22074 ), with nearly 65.8\% DDH similarity between them (Assih et al. 2002). These two species have indistinguishable phenotypes. The MLSA V group also included the strains LMG 10883, which is a member of Hauben's AFLP genomic group 1, and LMG 10881 and LMG 10882, which are not members of the Hauben's AFLP genomic groups. The strains LMG 10883 and LMG 10882 were reported by Hauben et al. (1999) with a DNA-DNA binding value of $6 \%$ between both strains. However, Coenye et al. (2004b) repeated the experiment and obtained a value of $83 \%$. These results confirm our data using the MLSA method.

\section{DISCUSSION}

The comparative genomic analysis of clinical and environmental isolates of Stenotrophomonas is of great interest. The analysis facilitates the rapid and reliable identification of these bacteria and contributes to our understanding of the adaptation strategies of this genus to different niches (Ryan et al. 2009). However, the precise identification and classification of Stenotrophomonas remains a problem. The band pattern methods (e.g., AFLP) and DDH techniques have been used to underpin the taxonomy of Stenotrophomonas. The data that are generated by these tools are often difficult to reproduce and are available only in relatively few laboratories (Coenye et al. 2004a). Moreover, this category of data cannot be used to build an online electronic classification.
Here, we proposed a rapid and cost-effective online scheme for molecular screening of the Stenotrophomonas isolates that was based on MLSA typing. Our scheme allowed the assignment of bacterial isolates and strains into well-characterised genomic groups to estimate genetic distances, to measure the intraspecific diversity and to identify putative new species.

The results of the MLSA analysis confirm that there is significant diversity within Stenotrophomoas spp. More importantly, our MLSA groups were in close agreement with the genomic groups that were classified by Hauben et al. (1999). We used AFLP fingerprint, 16S rRNA sequencing and DDH analyses. The results indicate that the partial genomic sequencing of housekeeping genes and ribosomal rRNAs provide sufficient information for the proper classification of these species.

Further studies that aim to refine and enhance the current MLSA scheme are currently under way in our laboratory. These studies will increase the number of loci and the length of sequence reads and will provide additional phenotypic information (e.g., multidrug resistance, adhesins, virulence factors) that are related to strains and isolates that are included in our database. Altogether, this new information should provide a reliable system of classification for this genus.

\section{ACKNOWLEDGEMENTS}

To Mrs. Thais Scudelletti, for revising and preparing our manuscript.

\section{REFERENCES}

Altschul SF, Gish W, Miller W, Myers EW, Lipman DJ 1990. Basic local alignment search tool. J Mol Biol 215: 403-410.

Araoka H, Baba M, Yoneyama A 2010. Risk factors for mortality among patients with Stenotrophomonas maltophilia bacteremia in Tokyo, Japan, 1996-2009. Eur J Clin Microbiol Infect Dis 29: 605-608.

Assih EA, Ouattara AS, Thierry S, Cayol JL, Labat M, Macarie H 2002. Stenotrophomonas acidaminiphila sp. nov., a strictly aerobic bacterium isolated from an upflow anaerobic sludge blanket (UASB) reactor. Int J Syst Evol Microbiol 52: 559-568.

Bishop CJ, Aanensen DM, Jordan GE, Kilian M, Hanage WP, Spratt BG 2009. Assigning strains to bacterial species via the internet. BMC Biol 7: 3.

Brady C, Cleenwerck I, Venter S, Vancanneyt M, Swings J, Coutinho T 2008. Phylogeny and identification of Pantoea species associated with plants, humans and the natural environment based on multilocus sequence analysis (MLSA). Syst Appl Microbiol 31: 447-460.

Coenye T, Vanlaere E, Falsen E, Vandamme P 2004a. Stenotrophomonas africana Drancourt et al. 1997 is a later synonym of Stenotrophomonas maltophilia (Hugh 1981) Palleroni and Bradbury 1993. Int J Syst Evol Microbiol 54: 1235-1237.

Coenye T, Vanlaere E, LiPuma JJ, Vandamme P 2004b. Identification of genomic groups in the genus Stenotrophomonas using gyrB RFLP analysis. FEMS Immunol Med Microbiol 40: 181-185.

Crossman LC, Gould VC, Dow JM, Vernikos GS, Okazaki A, Sebaihia M, Saunders D, Arrowsmith C, Carver T, Peters N, Adlem E, Kerhornou A, Lord A, Murphy L, Seeger K, Squares R, Rutter S, Quail MA, Rajandream MA, Harris D, Churcher C, Bentley SD, Parkhill J, Thomson NR, Avison MB 2008. The complete genome, comparative and functional analysis of Stenotrophomonas maltophilia reveals an organism heavily shielded by drug resistance determinants. Genome Biol 9: R74. 
Drancourt M, Bollet C, Raoult D 1997. Stenotrophomonas africana sp. nov., an opportunistic human pathogen in Africa. Int $J$ Syst Bacteriol 47: 160-163.

Ezaki B, Ogura T, Mori H, Niki H, Hiraga S 1989. Involvement of dnaK protein in mini-F plasmid replication: temperature-sensitive seg mutations are located in the dnaK gene. Mol Gen Genet 218: 183-189.

Falagas ME, Valkimadi PE, Huang YT, Matthaiou DK, Hsueh PR 2008. Therapeutic options for Stenotrophomonas maltophilia infections beyond co-trimoxazole: a systematic review. $J$ Antimicrob Chemother 62: 889-894.

Finkmann W, Altendorf K, Stackebrandt E, Lipski A 2000. Characterization of $\mathrm{N}_{2} \mathrm{O}$-producing Xanthomonas-like isolates from biofilters as Stenotrophomonas nitritireducens sp. nov., Luteimonas mephitis gen. nov., sp. nov. and Pseudoxanthomonas broegbernensis gen. nov., sp. nov. Int J Syst Evol Microbiol 50: 273-282.

Hanage WP, Fraser C, Spratt BG 2006. Sequences, sequence clusters and bacterial species. Philos Trans R Soc Lond B Biol Sci 29: 1917-1927.

Hauben L, Vauterin L, Moore ER, Hoste B, Swings J 1999. Genomic diversity of the genus Stenotrophomonas. Int J Syst Bacteriol 49: $1749-1760$

Heylen K, Vanparys B, Peirsegaele F, Lebbe L, De Vos P 2007. Stenotrophomonas terrae sp. nov. and Stenotrophomonas humi sp. nov., two nitrate-reducing bacteria isolated from soil. Int J Syst Evol Microbiol 57: 2056-2061.

Huson DH 1998. SplitsTree: analyzing and visualizing evolutionary data. Bioinformatics 14: 68-73.

Jolley KA, Feil EJ, Chan MS, Maiden MC 2001. Sequence type analysis and recombinational tests (START). Bioinformatics 17: 1230-1231.

Juhasz AL, Naidu R 2000. Enrichment and isolation of non-specific aromatic degraders from unique uncontaminated (plant and faecal material) sources and contaminated soils. J Appl Microbiol 89: $642-650$

Kaparullina E, Doronina N, Chistyakova T, Trotsenko Y 2009. Stenotrophomonas chelatiphaga sp. nov., a new aerobic EDTAdegrading bacterium. Syst Appl Microbiol 32: 157-162.

Kim HB, Srinivasan S, Sathiyaraj G, Quan LH, Kim SH, Bui TP, Liang ZQ, Kim YJ, Yang DC 2010. Stenotrophomonas ginsengisoli sp. nov., isolated from a ginseng field. Int J Syst Evol Microbiol 60: 1522-1526.

Maiden MC, Bygraves JA, Feil E, Morelli G, Russell JE, Urwin R, Zhang Q, Zhou J, Zurth K, Caugant DA, Feavers IM, Achtman M, Spratt BG 1998. Multilocus sequence typing: a portable approach to the identification of clones within populations of pathogenic microorganisms. Proc Natl Acad Sci USA 95: 3140-3145.

Minkwitz A, Berg G 2001. Comparison of antifungal activities and 16S ribosomal DNA sequences of clinical and environmental isolates of Stenotrophomonas maltophilia. J Clin Microbiol 39: 139-145.
Naser SM, Thompson FL, Hoste B, Gevers D, Dawyndt P, Vancanneyt M, Swings J 2005. Application of multilocus sequence analysis (MLSA) for rapid identification of Enterococcus species based on rpoA and pheS genes. Microbiology 151: 2141-2150.

Nicodemo AC, Paez JI 2007. Antimicrobial therapy for Stenotrophomonas maltophilia infections. Eur J Clin Microbiol Infect Dis 26: 229-237.

Nyc O, Matejková J 2010. Stenotrophomonas maltophilia: significant contemporary hospital pathogen. Folia Microbiol (Praha) 55: $286-294$

Palleroni NJ, Bradbury JF 1993. Stenotrophomonas, a new bacterial genus for Xanthomonas maltophilia (Hugh 1980) Swings et al. 1983. Int J Syst Bacteriol 43: 606-609.

Ramos PL, Van Trappen S, Thompson FL, Rocha RCS, Barbosa HR, De Vos P, Moreira-Filho CA 2011. Screening for endophytic nitrogen-fixing bacteria in Brazilian sugarcane varieties used in organic farming and description of Stenotrophomonas pavanii sp. nov. Int J Syst Evol Microbiol 61: 926-931.

Ryan RP, Monchy S, Cardinale M, Taghavi S, Crossman L, Avison MB, Berg G, van der Lelie D, Dow JM 2009. The versatility and adaptation of bacteria from the genus Stenotrophomonas. Nat Rev Microbiol 7: 514-525.

Saitou N, Nei M 1987. The neighbor-joining method: a new method for reconstructing phylogenetic trees. Mol Biol Evol 4: 406-425.

Sanchez MB, Hernandez A, Martinez JL 2009. Stenotrophomonas maltophilia drug resistance. Future Microbiol 4: 655-660.

Thompson FL, Gevers D, Thompson CC, Dawyndt P, Naser S, Hoste B, Munn CB, Swings J 2005. Phylogeny and molecular identification of vibrios on the basis of multilocus sequence analysis. Appl Environ Microbiol 71: 5107-5115.

Turner KM, Feil EJ 2007. The secret life of the multilocus sequence type. Int J Antimicrob Agents 29: 129-135.

Vega FE, Pava-Ripoll M, Posada F, Buyer JS 2005. Endophytic bacteria in Coffea arabica L. J Basic Microbiol 45: 371-380.

Wayne LG, Brenner DJ, Colwell RR, Grimont PAD, Kandler O, Krichevsky MI, Moore LH, Moore WEC, Murray RGE, Stackebrandt E, Starr MP, Truper HG 1987. Report of the ad hoc committee on reconciliation of approaches to bacterial systematics. Int J Syst Bacteriol 37: 463-464.

Willems A, Doignon-Bourcier F, Goris J, Coopman R, de Lajudie P, De Vos P, Gillis M 2001. DNA-DNA hybridization study of Bradyrhizobium strains. Int J Syst Evol Microbiol 51: 1315-1322.

Wolf A, Fritze A, Hagemann M, Berg G 2002. Stenotrophomonas rhizophila sp. nov., a novel plant-associated bacterium with antifungal properties. Int J Syst Evol Microbiol 52: 1937-1944.

Yang HC, Im WT, Kang MS, Shin DY, Lee ST 2006. Stenotrophomonas koreensis sp. nov., isolated from compost in South Korea. Int J Syst Evol Microbiol 56: 81-84. 
TABLE

Percentage DNA-DNA hybridization between Stenotrophomonas strains

\begin{tabular}{|c|c|c|c|c|c|c|c|c|c|c|c|c|c|c|c|c|c|c|c|}
\hline & $1^{a}$ & $2^{a}$ & $3^{a}$ & $4^{a}$ & $5^{a}$ & $6^{a}$ & $7^{a}$ & $8^{a}$ & $9^{a}$ & $10^{a}$ & $11^{a}$ & $12^{b}$ & $13^{b}$ & $14^{b}$ & $15^{b}$ & $16^{b}$ & $17^{b}$ & $18^{b}$ & $19^{b}$ \\
\hline 1 LMG 10996 & 100 & & & & & & & & & & & & & & & & & & \\
\hline 2 LMG 10991 & 84 & 100 & & & & & & & & & & & & & & & & & \\
\hline 3 ICB 194 & 64.8 & - & 100 & & & & & & & & & & & & & & & & \\
\hline 4 LMG $25348^{\mathrm{T}}$ S. pavanii & 58.1 & - & - & 100 & & & & & & & & & & & & & & & \\
\hline 5 LMG $22073^{\mathrm{T}}$ S. acidaminiphila & 17.7 & - & - & - & 100 & & & & & & & & & & & & & & \\
\hline 6 LMG $23369^{\mathrm{T}}$ S. koreensis & 12.3 & - & - & - & - & 100 & & & & & & & & & & & & & \\
\hline 7 LMG 958 S. maltophilia & 56.6 & - & 77.1 & 55.1 & - & - & 100 & & & & & & & & & & & & \\
\hline 8 LMG $22074^{\mathrm{T}}$ S. nitritireducens & 26.3 & - & - & 31.2 & 66.9 & - & - & 100 & & & & & & & & & & & \\
\hline 9 LMG $23958^{\mathrm{T}}$ S. terrae & 19.3 & - & - & - & - & - & - & - & 100 & & & & & & & & & & \\
\hline 10 LMG $23959^{\mathrm{T}} S$. humi & 16 & - & - & - & - & - & - & - & - & 100 & & & & & & & & & \\
\hline 11 LMG $24537^{\mathrm{T}}$ S. rhizophila & 24.5 & - & - & 30.7 & - & - & - & - & - & - & 100 & & & & & & & & \\
\hline 12 LMG 11004 & 65 & 89 & - & - & - & - & - & - & - & - & - & 100 & & & & & & & \\
\hline 13 LMG 11000 & 71 & - & - & - & - & - & - & - & - & - & - & - & 100 & & & & & & \\
\hline 14 LMG 11111 & - & 76 & - & - & - & - & - & - & - & - & - & - & - & 100 & & & & & \\
\hline 15 LMG 978 & - & - & - & - & - & - & 54 & - & - & - & - & - & - & - & 100 & & & & \\
\hline 16 LMG 980 & 53 & - & - & - & - & - & 55 & - & - & - & - & - & - & - & - & 100 & & & \\
\hline 17 LMG 10874 & - & - & - & - & - & - & 60 & - & - & - & - & - & - & - & - & - & 100 & & \\
\hline 18 LMG 10878 & - & - & - & - & - & - & 49 & - & - & - & - & - & - & - & - & - & - & 100 & \\
\hline 19 LMG 10877 & - & - & - & - & - & - & 51 & - & - & - & - & - & - & - & - & - & - & - & 100 \\
\hline
\end{tabular}

$a$ : data from our study; $b$ : data from Hauben et al. (1999) 


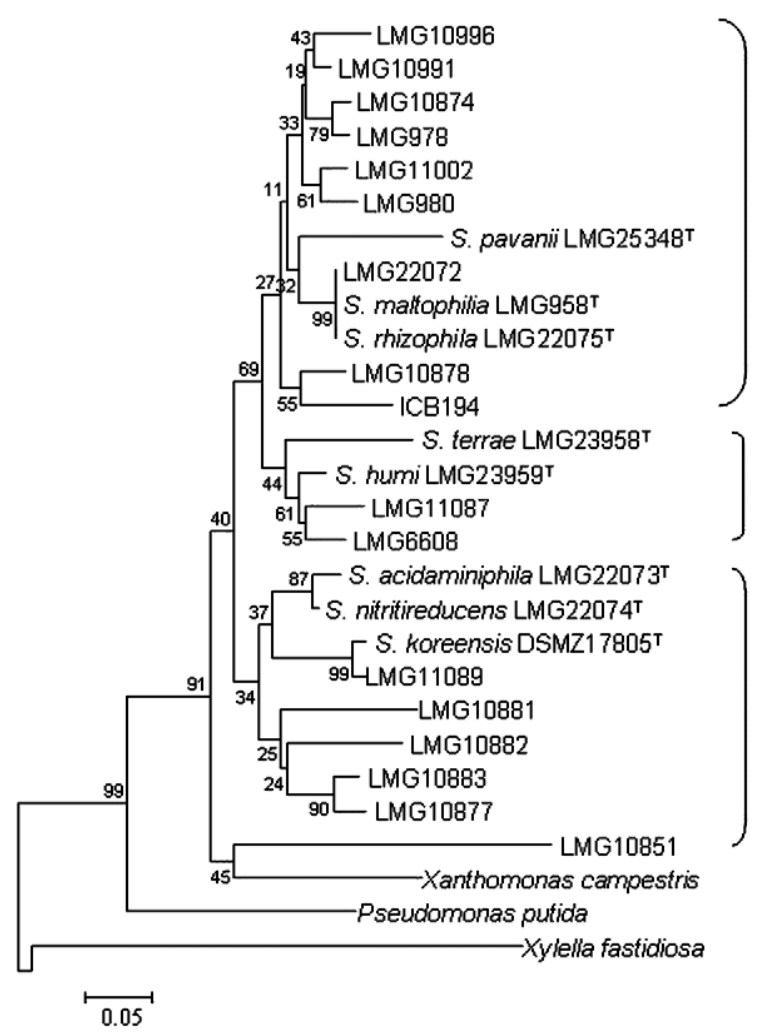

Neighbour-Joining phylogenetic tree based on the atpA gene sequences. Values of bootstrap after 1,000 repetitions are shown at the nodes. Pseudomonas putida, Xanthomonas campestris and Xylella fastidiosa were used as out-groups.

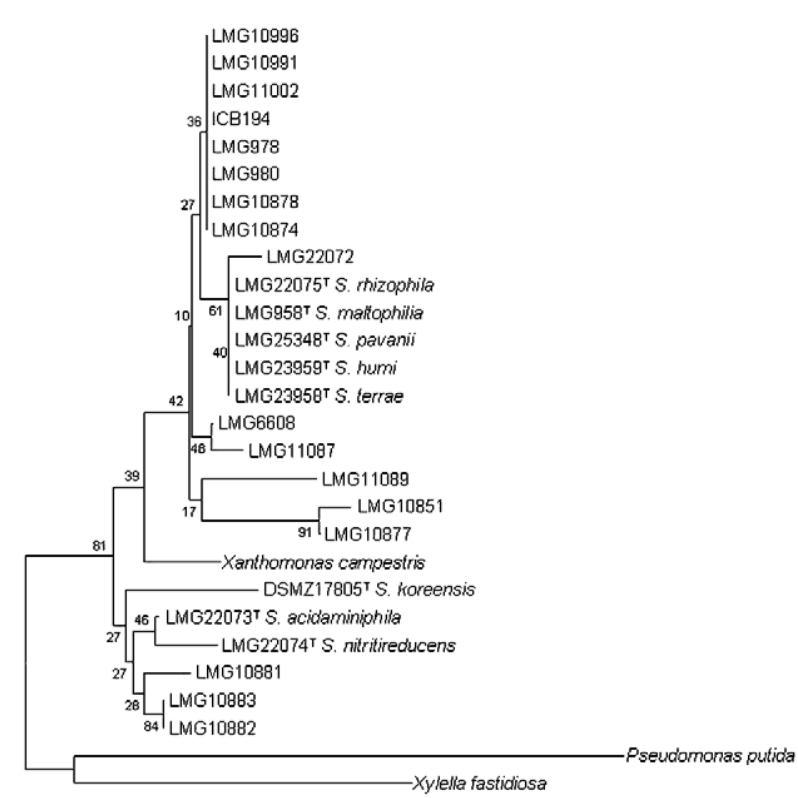

0.05

Neighbour-Joining phylogenetic tree based on the recA gene sequences. Values of bootstrap after 1,000 repetitions are shown at the nodes. Pseudomonas putida and Xylella fastidiosa were used as out-groups. 


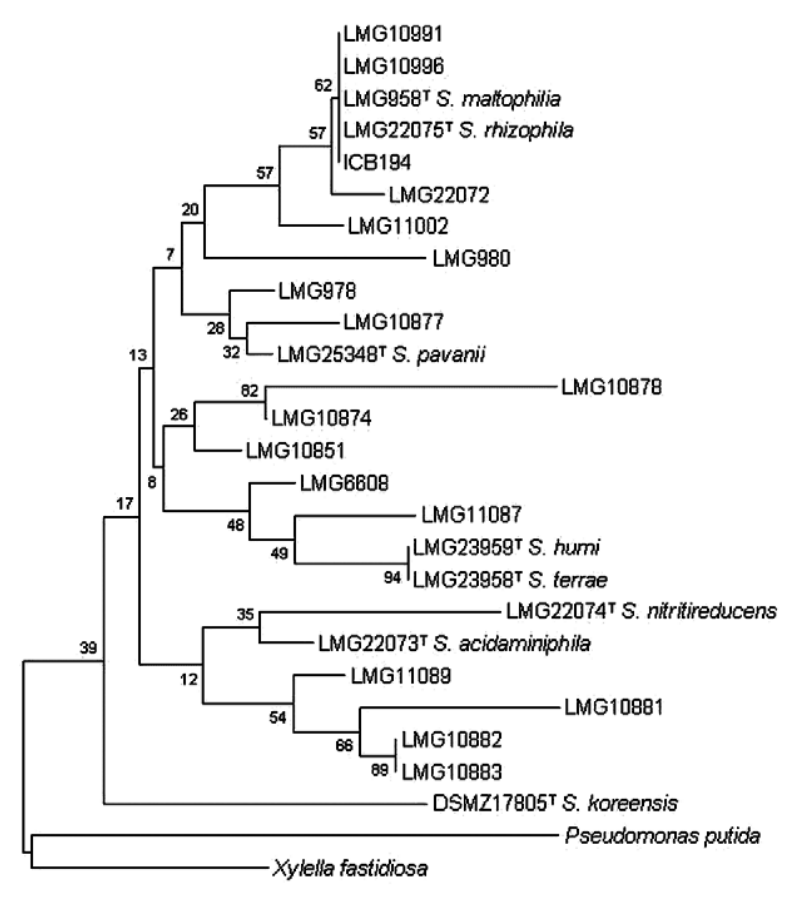

$\widetilde{0.01}$

Neighbour-Joining phylogenetic tree based on the rpoA gene sequences. Values of bootstrap after 1,000 repetitions are shown at the nodes. Pseudomonas putida, Xanthomonas campestris and Xylella fastidiosa were used as out-groups.

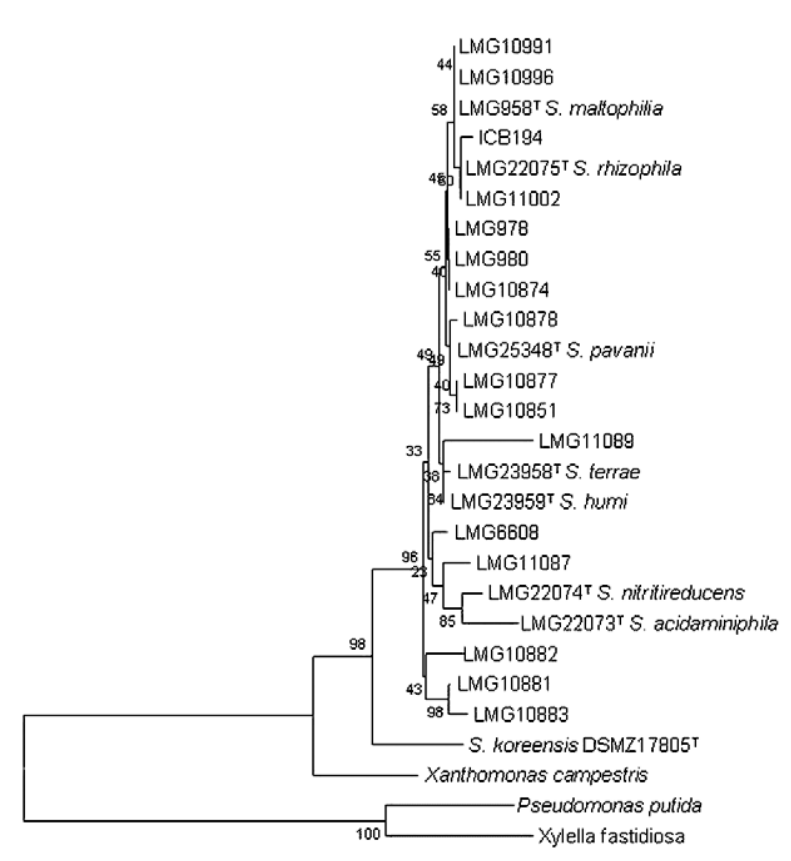

0.05

Neighbour-Joining phylogenetic tree based on the $u v r \mathrm{~B}$ gene sequences. Values of bootstrap after 1,000 repetitions are shown at the nodes. Pseudomonas putida, Xanthomonas campestris and Xylella fastidiosa were used as out-groups. 